\author{
Camila Horst Toigo ${ }^{1}$ \\ Marcelo Antonio Conterato ${ }^{2}$ \\ Paulo Dabdab Waquil ${ }^{3}$
}

\title{
Domicílios rurais do Território Zona Sul: condições de vida e percepções
}

\section{Introdução}

A criação dos Territórios Rurais, assentada na abordagem territorial, demandou a necessidade de implementar novas ferramentas para acompanhar as ações integradas de fomento ao desenvolvimento multidimensional promovidas pelas instituições governamentais, como o Índice de Condição de Vida (ICV). Conforme apontou a Secretaria de Desenvolvimento Territorial (SDT) (BRASIL, 2005a), tal demanda foi em busca de um indicador que representasse as mudanças percebidas no e pelo público-alvo.

Conforme Rambo et al. (2012), a ideia pautou-se em uma visão que buscava a integração dos indivíduos com o espaço em que viviam e com o poder público, buscando, a partir de interfaces e diálogos estabelecidos, uma construção conjunta para potenciais soluções de problemas existentes. Em contrapartida com as limitações metodológicas e conceituais de outros índices já existentes que pouco refletiam sobre condições de vida e desenvolvimento multifacetado, o ICV permitia, em certo grau, captar esses elementos a partir da própria percepção dos indivíduos (famílias rurais) residentes no território. Assim, a metodologia do índice foi pensada de modo a captar o que os indivíduos percebiam sobre suas condições de vida, buscando, ainda, reflexões sobre a eficácia ou ineficácia das ações do Estado em prol do desenvolvimento.

Nas últimas décadas, a intensificação e solidificação de novas reflexões que direcionaram as questões relacionadas ao meio rural e ao bem-estar para uma nova discussão criou espaço para o interesse por novas

\footnotetext{
${ }^{1}$ Economista, mestre em desenvolvimento rural pela Universidade Federal do Rio Grande do Sul (UFRGS) e doutoranda em Desenvolvimento Econômico pela Pontifícia Universidade Católica do Rio Grande do Sul (PUC-RS). E-mail: camilahorstoigo@gmail.com.

2 Professor adjunto III da UFRGS, vinculado ao Departamento de Economia e Relações Internacionais (DERI) e ao Programa de Pós-Graduação em Desenvolvimento Rural (PGDR). E-mail: marcelo.conterato@ufrgs.br.

3 Mestrado em Economia Rural pela UFRGS e doutorado em Economia Agrícola pela University of Wisconsin, Madison - EUA, professor associado da UFRGS. E-mail: waquil@ufrgs.br.
} 
ferramentas analíticas capazes de captar questões importantes sobre o desenvolvimento. A possibilidade e mesmo necessidade de discutir o desenvolvimento rural sob novos enfoques foram ressaltadas pela emergência das novas ruralidades e novas abordagens assentadas na revitalização do rural e na evolução do próprio conceito (FAVARETO 2006), o qual desassociou-se de questões exclusivamente agrícola e expandiu-se à noção de "tecido econômico e social diversificado (KAGEYAMA, 2008, p. 28).

Assim, o Brasil passou a introduzir novos direcionamentos ao meio rural, sobretudo no que diz respeito à operacionalização e normatização de políticas públicas e ferramentas de análises. Visto que já era equivocado compreender o rural como sinônimo de agrário, uma abordagem territorial que lhe desassociasse da perspectiva setorial e produtivista passou a ser assimilada. Essa nova dinâmica territorial propôs, então, a necessidade de arquitetar políticas e ações públicas que incentivassem e encorajassem a materialização de projetos voltados à valorização do meio rural e à promoção multidimensional do desenvolvimento (ABRAMOVAY, 1999) de forma a gerar as oportunidades e os recursos que possibilitam a realização das escolhas pessoais de cada indivíduo (SEN, 2010) e permitem o incremento da qualidade de vida das populações rurais.

Foi, portanto, assentando-se nos princípios da abordagem territorial do desenvolvimento rural e no caráter multidimensional da Abordagem das Capacitações de Amartya que o Índice de Condição de Vida foi estruturado em três dimensões: a) os fatores que favorecem o desenvolvimento (os quais relacionavam-se aos intitulamentos, os meios para se alcançar o desenvolvimento, os recursos acessados); b) as características do desenvolvimento, ou seja, os elementos de conversão dos meios para os fins e, por último; c) os efeitos do desenvolvimento, representados pelas capacitações e pelos funcionamentos individuais. Permitindo uma análise múltipla, ele foi aplicado para o Território Rural Zona Sul do Rio Grande do Sul com o intuito de acompanhar as condições de vida das famílias rurais nele residentes.

No Território Rural Zona Sul do Rio Grande do Sul a amostra abrangeu 280 domicílios rurais. Neste total estavam inseridos domicílios que possuíam práticas produtivas agropecuárias para comércio e/ou autoconsumo - com caracterização de agricultura familiar e não familiar e domicílios sem produção, voltados sobretudo para moradia.

Com base na amostra composta por domicílios rurais com características heterogêneas, este artigo busca verificar se as percepções sobre as condições de vida das famílias residentes nestes domicílios divergem. A constatação da existência ou não de diferenças significativas pauta-se nos seguintes grupos: domicílios com produção agropecuária 


\section{Camila Horst Toigo, Marcelo Antonio Conterato e Paulo Dabdab Waquil}

versus domicílios de moradia, e domicílios de agricultura familiar versus domicílios de agricultura não familiar. Para garantir a exequibilidade da pesquisa são feitas inferências estatísticas a partir do Teste de Comparação de Médias (Teste T, de Studant), que permitem verificar a aceitação da hipótese nula de que as médias são iguais - isto é, não há diferença nas percepções entre dos grupos analisados - ou a rejeição da mesma. Os resultados obtidos trazem reflexões gerais e pontuais sobre o desenvolvimento multidimensional no território e sobre situações de vulnerabilidade.

\section{Pensando as condições de vida a partir de um índice}

No âmago do debate sobre desenvolvimento e ruralidade, compreender o desenvolvimento como um processo, uma situação ou uma condição que proporcionaria melhorias nas condições de vida para as sociedades se manifestava, portanto, como o mais adequado (SCHNEIDER; FREITAS, 2013). Entender o desenvolvimento era mais complexo do que uma simples análise dos níveis de renda dos indivíduos, principalmente em virtude do seu caráter multidimensional.

Nas últimas décadas, temas referentes às condições de vida, à pobreza, à vulnerabilidade, aos meios de sobrevivência, aos meios de vida, à liberdade e aos direitos começaram a ganhar espaço mais solidamente nas pautas políticas e nos estudos dentro da academia. Essas novas proposições impulsionaram novos estudos, formulações $e$ implementações de políticas de desenvolvimento. A partir daí iniciou-se "uma nova fase de estudos e referências que buscaram reorientar as ações e as concepções" deste conceito (PERONDI; SCHNEIDER, 2012, p. 118).

Assim, estudos que possibilitassem a observância dos funcionamentos, das capacitações, da capacidade de agência dos atores sociais e a forma pela qual estes conseguem aprimorar suas condições de vida tornaram-se fundamentais para os estudiosos do meio rural, visto que estar vulnerável significava muito mais do que apresentar-se abaixo da linha da pobreza - esta que, para muitos autores, se compõe como a principal referência do que é ser ou estar pobre (SCHNEDIER; FREITAS, 2013).

Ainda, após a retomada da democracia na década de 1980, mudanças significativas na condução política e institucional passaram a alterar as ações do Estado brasileiro. Conforme aponta Fernadéz, Amin e Vigil (2008), o desenvolvimento como um processo deixou de ser compreendido a partir da visão top-down e passou a ser analisado sob uma perspectiva bottom-up. Isto é, sob uma ótica ascendente (de baixo para cima) as regiões passaram a ser entendidas como promotoras do seu próprio desenvolvimento, especialmente com a ação integrada de múltiplos atores. 
As novas formas de conduzir as ações e de relacionar-se com as organizações, com as instituições e, até mesmo, com a sociedade civil, passaram a sustentar-se sob uma nova abordagem que emergia: a abordagem territorial do desenvolvimento rural. De acordo com Schneider (2004), essa nova visão pressupôs uma melhor adequação para o tratamento de problemas concretos, seja sob uma ótica analítica, seja conceitual, que envolviam relações sociais, econômicas, políticas e institucionais e ações entre os indivíduos, o ambiente e conjuntura dentro dos quais se inseriam. A abordagem territorial do desenvolvimento rural sustentava a perspectiva de que as soluções para os problemas existentes nesses espaços estavam-se inseridas neles mesmos.

Foi sob essa conjuntura conceitual que o Estado brasileiro passou a planejar a condução de suas ações no âmbito das políticas públicas voltadas para o meio rural. Destarte, foi implementada, nos primeiros anos do novo milênio (2003), a Secretaria de Desenvolvimento Territorial (SDT) junto ao Ministérios do Desenvolvimento Agrário. A partir disso foi criado o Programa de Desenvolvimento Sustentável de Território Rurais (PRONAT), tendo como base para a sua execução a criação dos diversos territórios. O Território Rural Zona Sul (TZS) do estado do Rio Grande do Sul surgiu como território rural com o Programa Territórios da Cidadania (PTC) promovido pelo Ministério do Desenvolvimento Agrário (MDA) em 2008 (RAMBO et al., 2012).

Em razão da necessidade de dispor um acompanhamento mais robusto dos territórios rurais, sobretudo em relação às suas dinâmicas e potenciais ações necessárias em prol do desenvolvimento multidimensional dos mesmos, a SDT articulou-se com 27 universidades e 37 territórios rurais para acompanhar, avaliar e colher informações sobre os territórios a partir do desenvolvimento de novos processos e ferramentas (RAMBO et al., 2012). Assim, o Índice de Condição de Vida foi criado com base na experiência de um grupo de pesquisadores vinculados ao Programa de Pós-Graduação em Desenvolvimento Rural da Universidade Federal do Rio Grande do Sul na validação do projeto do Índice de Desenvolvimento Sustentável (IDS) - elaborado pela professora Angela Kageyama - e do Biograma como um instrumento interessante para realizar análise comparativas de mensuração e representação múltiplas dos processos de desenvolvimento territorial (BRASIL, 2007).

A limitação do IDS, pautada essencialmente na dependência da disponibilidade e da atualização dos dados secundários disponíveis, motivou a SDT demandar uma ferramenta complementar. Portanto, a partir da arquitetura teórica e metodológica do ICV, o desígnio passou a ser um acompanhamento mais direto sobre as condições de vida das populações rurais, pautadas nas percepções dos próprios indivíduos. Com isso, visou-se inferir sobre as ações institucionais promovidas nos 


\section{Camila Horst Toigo, Marcelo Antonio Conterato e Paulo Dabdab Waquil}

territórios buscando apontar, por fim, os resultados, além de conjecturar melhorias, caso houvesse necessidade (BRASIL, 2007).

Assentando-se na Abordagem das Capacitações de Amartya Sen, a construção do ICV apropriou-se de conceitos senianos, como capacitações, funcionamentos, intitulamentos para possibilitar uma análise multidimensional do desenvolvimento. A multidimensionalidade surge como um contraste às teorias tradicionais mais restritas pautadas na unidimensionalidade e caracterizadas essencialmente pelo nível de renda monetária. Ao possuir instâncias/dimensões pautadas nas concepções de desenvolvimento de Sen (processo de remoção de privações e expansão de liberdades, capacidades e oportunidades), os resultados obtidos expressaram uma avaliação da capacidade de escolha dos indivíduos, "realizações de ações ou do alcance de estados [funcionamentos] considerados desejáveis" (RAMBO et al., 2012).

Segundo Robeyns (2003, p. 5), a Abordagem das Capacitações é usada em diversos campos e para melhor avaliar a "variedade de aspectos do bem-estar das pessoas, tais como o bem-estar individual, desigualdade e pobreza". ${ }^{4}$ Assim, o enfoque nas capacidades/capacitações serve de maneira abrangente na avaliação e no acompanhamento do bem-estar individual e coletivo, além de auxiliar na formulação de políticas públicas relacionadas às mudanças sociais na sociedade.

Com base nisso, o índice foi composto por três instâncias. A primeira delas representava os condicionantes do desenvolvimento humano, ou seja, os meios que possibilitam alcançá-lo. A segunda instância representava as características do desenvolvimento e relacionava-se com os elementos conversores dos meios em fins (conversão dos intitulamentos/recursos em funcionamentos e capacitações). Por fim, a terceira instância possibilitava apontar os efeitos dos processos de desenvolvimento. Esta instância referia-se aos funcionamentos, às liberdades de fato realizadas e ao conjunto capacitário dos indivíduos residentes nos domicílios rurais estudados (BRASIL, 2007; RAMBO et al., 2015). A cada uma das instâncias se associaram oito indicadores multidimensionais que traziam informações sobre renda, educação, saúde, meio ambiente, características da família e do domicílio, dinâmica produtiva, moradia.

Ressalta-se, pois, um elemento marcante e peculiar na metodologia do ICV: os resultados são obtidos a partir das percepções dos próprios indivíduos sobre suas condições de vida. Assim, tais percepções, as quais buscaram ser captadas pelo ICV, possuíam o intento de, baseando-se na abordagem das Representações Sociais de Moscovici (2003), apontar o

\footnotetext{
${ }^{4}$ No original: "[...] variety of aspects of people's well-being, such as individual well-being, inequality and poverty."
} 
pensamento social em relação ao individual de forma que explicasse a pluralidade de pensamentos dos atores sociais envolvidos na pesquisa.

Segundo Jodelet (1989), as representações sociais são associadas às redes de interpretação que norteiam as relações, as condutas e as comunicações sociais dos indivíduos entre si, uns com os outros e com o mundo. Conforme aponta Rambo et al., (2012, p. 11):

A história do grupo e dos indivíduos, com seus símbolos, códigos e normas de conduta próprias, baliza suas práticas, e está diretamente relacionada ao desenvolvimento das diferentes representações subjetivas. Desta forma, pode-se afirmar que os objetos, fatos e pessoas representados refletem a multiplicidade de experiências que configura a realidade concreta e com isto as semelhanças e diferenças entre grupos ou mesmo entre os indivíduos que fazem parte do mesmo meio social. Assim, as representações sociais podem ser utilizadas para definir as relações que balizam as identidades na sociedade.

A partir disso, a apreensão da diversidade de sentidos, ideias e olhares permite compreender, dentro de uma determinada sociedade ou grupo de indivíduos, as diferenças e semelhanças a respeito de uma realidade específica. Visto que para Moscovici (2003) a diversidade de ideias reflete a heterogeneidade das sociedades modernas no que diz respeito às representações, a forma como o conhecimento é apropriado pelos indivíduos e organizado em atitudes e opiniões também não é homogêneo.

Assim, o objetivo do índice em assentar-se nas percepções foi avaliar essa diversidade de opiniões, valores, atitudes e pensamentos no que diz respeito às condições de vida dos pesquisados de forma a inferir como o desenvolvimento é percebido para essas pessoas no TZS. Assim, buscouse verificar se as percepções das famílias diferiam devido às características do domicílio (com produção agropecuária, com produção agropecuária familiar, com produção agropecuária não familiar ou apenas de moradia).

\section{Aporte metodológico}

O universo desta pesquisa constituiu-se na população rural residentes nos 25 municípios que compõem o TZS. Foi realizada uma amostra de seleção aleatória entre os Setores Censitários incluídos nesse universo, de modo que dez Setores Censitários foram selecionados, abrangendo nove municípios dos 25 que compõem o Território Rural Zona Sul. São eles: Aceguá, Canguçu (dois Setores Censitários), Cerrito, Hulha Negra, Pedro 
Osório, Pinheiro Machado, Piratini, SantaVitória do Palmar e São Lourenço do Sul.

A pesquisa foi realizada no ano de 2010 e o número de famílias em domicílios rurais totalizou 280.

Do total das 280 famílias entrevistadas, 238 inseriam-se no grupo de domicílios com produção agropecuária e 42 no grupo sem produção agropecuária. Do total dos 238 domicílios com produção agropecuária no território, 189 deles foram classificados como pertencentes à agricultura familiar, enquanto 49 domicílios como produtores não familiares.

Com vistas a convergir para o objetivo do artigo, foram realizados testes $\mathrm{T}$ para comparação de médias supondo variâncias diferentes entre os dados dos domicílios rurais. A hipótese nula pautou-se na igualdade entre as médias, corroborando a não divergência de percepções entre os grupos. Em contraponto, a hipótese não nula indicava que as condições de vida eram percebidas diferentemente para os diferentes grupos de domicílios.

A comparação entre as médias ocorreu entre os seguintes grupos: domicílios rurais com produção agropecuária (238 domicílios) versus domicílios rurais sem produção (42 domicílios); e domicílios rurais com características de agricultura familiar (189 domicílios) e domicílios rurais com características não familiares (49 domicílios). Frisa-se, pois, que estes dois últimos compuseram o grupo de domicílios com produção agropecuária.

O primeiro teste realizado considerou apenas as percepções dos grupos com produção e sem produção em relação aos indicadores da Instância 3 do Índice de Condição de Vida. A razão para esta limitação pautou-se em uma questão metodológica do próprio ICV: os domicílios sem produção agropecuária não correspondiam aos indicadores considerados nas duas primeiras instâncias, logo, não foi possível obter respostas dos mesmos. Os testes posteriores pautaram-se nas percepções correspondentes a cada uma das instâncias dos grupos de agricultura familiar e não familiar.

\section{Domicílos rurais do TZS: condições de vida e percepções}

As características e particularidades de cada indivíduo, família e/ou domicílios incidem e resultam em tipos distintos de liberdades, em capacidades diferentes e realizações de funcionamentos variados. $\mathrm{O}$ bemestar de uma pessoa - que muito pode ser compreendido como um índice de funcionamentos individuais - também depende de fatores diversos intrínseco à ela (elementos pessoais, sociais, metabólicos) ${ }^{5}$ ou não (elementos institucionais e conjunturais relacionado aos mercados, à política, à infraestrutura básica disponível para a sociedade) (SEN, 1999; 2010).

\footnotetext{
${ }^{5}$ Quando os funcionamentos estão relacionados a fatores nutricionais, por exemplo, a taxa de metabolismo é um elemento importante a ser considerado em conjunto com outras diversas variáveis como tamanho do corpo, idade, sexo, níveis de atividade, condições médicas (SEN, 1999).
} 
O portfólio de capitais ${ }^{6}$ (produtivo, natural, financeiro, social, humano) acessados pelos indivíduos e o conjunto capacitário formado a partir das liberdades adquiridas, considerando-se as variações interpessoais, podem refletir sobre as condições de vida, as capacidades, as escolhas e até mesmo sobre as limitações e privações de uma pessoa ou família. Assim, mais importante do que avaliar o bem-estar e a qualidade de vida em termos monetários é analisá-los em termos de oportunidades e capacidades (UNITED NATIONS DEVELOPMENT PROGRAMME, 2014).

Um dos desafios impostos aos pesquisadores contemporâneos, sobretudo aos brasileiros, é desvendar os processos e as dinâmicas que incidem na atual configuração diversificada do rural. $\mathrm{O}$ acesso a bens e serviços da população residente neste espaço reflete o quão participativa ela é e o quão inserida ela está nos resultados consequentes do progresso social na sociedade. Todavia, a sustentabilidade da reprodução social e local depende da igualdade de chances aos cidadãos e das oportunidades econômicas, culturais e sociais disponíveis para acesso. No meio rural, poucos destes fatores são facilmente apropriados pelos indivíduos, o que os torna fragilizados e vulneráveis multidimensionalmente (WANDERLEY, 2009).

Segundo Schneider (2009), nas últimas décadas o setor primário gaúcho e dos demais estados brasileiros apresentou um desenvolvimento econômico nunca igual visto antes. Acompanhado deste cenário, políticas públicas voltadas para a promoção do desenvolvimento rural passaram a ser difundidas entre as elites intelectuais brasileiras como forma de repensar os temas agrários e o espaço rural. Não obstante, o debate sobre a dinâmica da agricultura familiar frente às demais configurações sociais e produtivas foram ganhando força.

Dada a importância das atividades agropecuárias na agricultura sulina, sobretudo nos territórios rurais como Território Zona Sul, e dado o reconhecimento de "que a agricultura ocupa um lugar de destaque no espaço rural" (SCHNEIDER, 2003, p. 100), justifica-se a comparabilidade entre os domicílios com produção primária e os domicílios sem produção e os domicílios de agricultura familiar e não familiar. A observância das percepções entre esses grupos permite inferir, entre outros elementos, algumas oportunidades dos cidadãos envolvidos dentro do "processo" de desenvolvimento multidimensional no território. Ainda, permite refletir sobre os efeitos das ações promovidas pelas instituições para o encalce do bem-estar da população rural do TZS como um todo, sem ser consideradas as segmentações sociais e produtivas.

A primeira análise pautou-se na comparação entre os domicílios com produção agropecuária e os domicílios sem produção agropecuária

6 Ver: ELLIS, Frank. Rural Livelihoods and Diversity in Developing Countries. (2000); CHAMBERS, Robert; CONWAY, Gordon. (1991).“Sustainable rural livelihoods: practical concepts for the 21st century". [S.1.], 1991. (IDS Discussion Paper, 296). 


\section{Camila Horst Toigo, Marcelo Antonio Conterato e Paulo Dabdab Waquil}

(notadamente de moradia). Novamente ressalta-se que as duas primeiras instâncias do ICV abrangeram apenas as percepções das famílias de domicílios com produção agropecuária. Sendo assim, as comparações entre as instâncias 1 e 2 ficaram impossibilitadas, permitindo apenas a análise comparativa da última instância. Portanto, tão somente foi possível verificar a existências de diferenças nas percepções em termos de funcionamentos realizados, sendo excluída a análise em relação aos capitais e recursos acessados e meios de conversão.

Na Tabela 1 estão identificados os indicadores da Instância 3 comparados entre os dois grupos de domicílios. A média da instância enquadrou-se em um nível médio-alto ${ }^{7}$ para os domicílios com produção e médio para os domicílios sem produção.

Tabela 1 - ICV da Instância 3 e frequência por grupos de domicílios

\begin{tabular}{ccccc}
\hline \multicolumn{5}{c}{ INSTÂNCIA 3 } \\
\hline \multicolumn{3}{c}{ Com produção } & \multicolumn{2}{c}{ Sem produção } \\
\hline $\begin{array}{c}\text { Indicadores } \\
\text { Condições de alimentação } \\
\text { e nutrição }\end{array}$ & Frequência & Média & Frequência & Média \\
$\begin{array}{c}\text { Condições de saúde } \\
\text { Permanência dos }\end{array}$ & 238 & 0,750 & 42 & 0,738 \\
$\begin{array}{c}\text { membros da família no } \\
\text { domicílio }\end{array}$ & 238 & 0,642 & 42 & 0,577 \\
$\begin{array}{c}\text { Situação econômica } \\
\text { Situação ambiental } \\
\text { Participação em }\end{array}$ & 238 & 0,588 & 42 & 0,810 \\
organizações comunitárias \\
$\begin{array}{c}\text { Participação política } \\
\text { Participação em }\end{array}$ & 238 & 0,592 & 42 & 0,631 \\
atividades culturais & 238 & 0,631 & 42 & 0,536 \\
\hline Total da Instância & 238 & 0,508 & 42 & 0,536 \\
\hline
\end{tabular}

Fonte: Elaborada pela autora com base nos dados do SGE (2015).

Com base nas médias dos indicadores expostos acima, o teste $\mathrm{T}$ realizado com 54 graus de liberdade e $95 \%$ de confiança rejeitou a hipótese nula de igualdade entre as médias, segundo os dados apontados

7 O ICV segmenta seus resultados da seguinte forma: de 0 até 2,00: baixo; de 0,20 até 0,40: Médio-baixo; de 0,40 até 0,60: Médio; de 0,60 até 0,80: Médio-Alto; e de 0,80 até 1,00: Alto. 
na Tabela 2. Isto corrobora a existência de percepções distintas entre os dois grupos em relação as suas condições de vida.

Tabela 2 - Estatísticas do teste T para comparação de médias supondo variâncias diferentes - domicílios com produção e sem produção

\begin{tabular}{lll}
\hline & $C P$ & $S P$ \\
\hline Média & 3,60609 & 3,39286 \\
Variância & 0,22683 & 0,25806 \\
Observações & 238 & 42 \\
Graus de liberdade & 54 & \\
Estatística t calculado & 2,531120024 & \\
Estatística t bi-caudal & 2,004879288 & \\
\hline
\end{tabular}

Fonte: Elaborada pela autora com base nos dados do SGE (2015).

Aponta-se, assim, que as famílias que apresentavam dinâmicas produtivas agropecuárias percebiam suas realizações de maneira mais positivas, diferentemente das famílias cujo domicílio obtinha função apenas de moradia. Para aquelas, sete dos oito indicadores tiveram melhores níveis, corroborando melhores percepções em termos de funcionamentos. A partir disso, observa-se que as atividades primárias possuíam um papel marcante na sustentação e/ou promoção da qualidade de vida das famílias rurais do TZS.

Esta constatação guia para o questionamento das possíveis razões que levaram as famílias de agricultores a perceberem suas condições de vida melhores. As razões podem ser diversas e peculiares, não adquirindo um caráter homogêneo e universal. Todavia, há algumas convergências de ideias entre diversos autores, como Schneider (2009), Wanderley (2009), Van der Ploeg et al. (2000; 2008), Kageyama (2008), que ressaltam uma dinâmica nova e mais forte do meio rural que incide positivamente nas propriedades rurais com produção agrícola.

Dentre essas ideias, destaca-se a maior autonomia das famílias agricultoras para diversificarem seus meios de vida de modo a não se exporem às situações adversas e de vulnerabilidade multidimensional (as quais podem levar à situação de pobreza). De acordo com Van der Ploeg et al. (2000), a execução de diversas atividades, que tornam as famílias pluriativas, criaram novas estratégias de reprodução social, identidades, práticas, inter-relações e redes de trabalho.

Outro fator destacado são os plurirendimentos. Em concordância com Schneider (1999), domicílios rurais pluriativos dedicam-se a 


\section{Camila Horst Toigo, Marcelo Antonio Conterato e Paulo Dabdab Waquil}

outras atividades dentro ou fora do estabelecimento, além daquelas intrínsecas à produção agrícola, o que resulta em outras fontes de renda.

Famílias envolvidas na produção tendem a ter rendas de fontes variadas, como de políticas públicas, transferência de renda, comércio, processamento, manufatura, enquanto famílias que apenas moram no domicílio rural limitam-se a rendas advindas da aposentadoria, de pensões, transferência de renda e/ou de uma possível ocupação no mercado de trabalho. Aqui, a autonomia também é um elemento diferencial: enquanto famílias agricultoras conseguem diversificar suas estratégias dados as variadas fontes de renda, famílias não produtoras não possuem o mesmo incentivo.

Escher et al. (2014) destacam a importância das receitas advindas das atividades não agropecuárias, das aposentadorias e das transferências governamentais, sobretudo para os estabelecimentos da agricultura familiar que, segundo os autores, são mais sujeitos às situações de pobreza, vulnerabilidade e insegurança alimentar. Em termos comparativos, os autores apontam que as receitas agropecuárias possuem uma importância maior para os agricultores não familiares enquanto as aposentadorias, pensões e transferências de renda mostram-se pouco significativas. O oposto, portanto, ocorre nos estabelecimentos familiares.

Em relação ao acesso aos recursos e à conversão destes em realizações e funcionamentos, não se obteve dados para os domicílios sem produção. Por isso, não houve como apontar, de maneira comparativa, possível existência de privações mais ou menos intensas enfrentadas pelas famílias dos dois grupos de domicílios que pudessem justificar e corroborar com maior precisão a diferença nas percepções.

As análises comparativas posteriores assentaram-se na observância das percepções dos domicílios com produção agropecuária do tipo familiar e domicílios com produção agropecuária do tipo não familiar. Novamente, os testes buscaram verificar a existência ou não de diferenças nas percepções dos domicílios. Para isso, realizaram-se três testes, cada um referente a cada instância.

Como já mencionado, do total dos 238 domicílios com produção agropecuária no território, 189 deles foram classificados a partir de critérios objetivos como pertencentes à agricultura familiar por enquadrarem-se nos requisitos da Lei $n^{\circ} 11.326$, de 24 de julho de 2006, enquanto 49 domicílios enquadraram-se como não familiares. 
Para fins de comparação, a Tabela 3 traz todos os indicadores respectivos a cada uma das três instâncias do ICV para os domicílios de agricultura familiar e não familiar. É possível observar que os indicadores referentes ao capital financeiro (situação da renda, diversificação das fontes de renda, acesso aos mercados, acesso às políticas públicas, acesso à assistência técnica) apresentaram as piores percepções.

As famílias que exerciam práticas produtivas familiares apresentaram médias mais altas para os indicadores supramencionados. Todavia, é importante destacar que as médias ${ }^{8}$ mais baixas para os dois grupos refletiram a existência de obstáculos e dificuldades que deixaram os domicílios à mercê de situações complicadas, sobretudo em termos monetários, como difícil acesso ao crédito para expandir a produção, o empreendimento ou o consumo, complicações para inserirem-se em políticas públicas e programas governamentais (como PRONAF, Bolsa Família, PAA) para incrementar a renda, encontrar mercados para sua produção e/ou saciar as necessidades básicas. São justamente essas privações que incidem diretamente sobre a qualidade de vida dessas famílias ao inibir a expansão das suas liberdades e a realização de funcionamentos diversos (SEN, 2010), uma vez que, segundo Ellis (2000), o capital financeiro permite converter-se em outros tipos de capitais.

Os indicadores da Instância 2 também apresentaram médias mais elevadas e percepções mais otimistas para os domicílios com produção não familiar. Os resultados referentes à situação da renda familiar (recursos e capitais monetários disponíveis e acessados) continuaram a revelar um cenário mais satisfatório para esse grupo de domicílios.

Concernente à renda familiar, além da renda agrícola, os proventos advindos das políticas de transferência de renda eram presentes nos domicílios de agricultura familiar, como se observa na Tabela 4, o que vai ao encontro do que fora corroborado por Escher et al. anteriormente. Isto indica a permanência de rendas baixas, uma vez que as famílias se enquadravam como beneficiárias. Essas famílias poderiam estar, assim, sujeitas à pobreza monetária e a um efeito multiplicador incidente sobre a realização dos funcionamentos básicos e complexos e sobre a expansão das liberdades.

\footnotetext{
8 Como o resultado do ICV varia de 0 a 1, quanto mais próximo de 1 , melhores são as condições de vida percebidas pelos indivíduos. A interpretação e a análise das médias dos indicadores e das instâncias também levam em consideração essa escala. Portanto, quanto mais longe de 1 for a média de um determinado indicador, pior este está sendo percebido.
} 


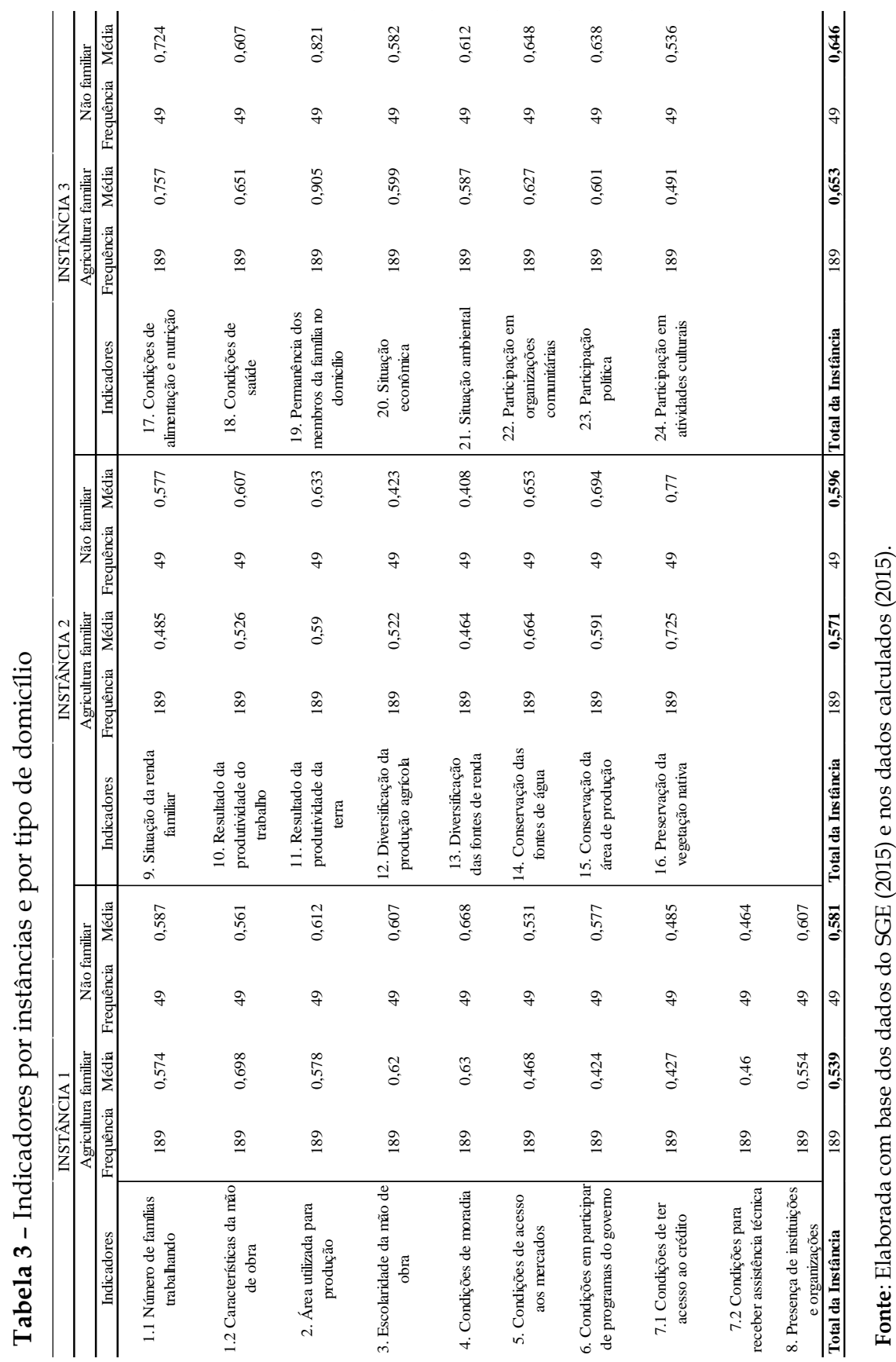


Tabela 4 - Fontes de renda e número de domicílios familiares e não familiares que abrangiam cada uma delas

\begin{tabular}{|c|c|c|c|}
\hline $\begin{array}{l}\text { Domicílios de } \\
\text { agricultura familiar }\end{array}$ & $\begin{array}{l}\text { Número de } \\
\text { domicílios } \\
\text { (de 189) }\end{array}$ & $\begin{array}{l}\text { Domicílios de } \\
\text { agricultura não familiar }\end{array}$ & $\begin{array}{l}\text { Número de } \\
\text { domicílios } \\
\text { (de 49) }\end{array}$ \\
\hline Produção agrícola & 189 & Produção agrícola & 39 \\
\hline $\begin{array}{l}\text { Trabalho agrícola para } \\
\text { terceiros }\end{array}$ & 49 & $\begin{array}{l}\text { Trabalho agrícola para } \\
\text { terceiros }\end{array}$ & 18 \\
\hline Trabalho não agrícola & 29 & Trabalho não agrícola & 14 \\
\hline Artesanato/manufatura & 14 & Artesanato/manufatura & 1 \\
\hline Turismo rural & 1 & Turismo rural & 1 \\
\hline $\begin{array}{l}\text { Processamento ou } \\
\text { beneficiamento de } \\
\text { produtos }\end{array}$ & 8 & $\begin{array}{l}\text { Processamento ou } \\
\text { beneficiamento de } \\
\text { produtos }\end{array}$ & 1 \\
\hline Aposentadoria/pensão & 51 & Aposentadoria/pensão & 31 \\
\hline $\begin{array}{l}\text { Programa de } \\
\text { transferência de renda }\end{array}$ & 72 & $\begin{array}{l}\text { Programa de transferência } \\
\text { de renda }\end{array}$ & 12 \\
\hline Arrendamento de terra & 10 & Arrendamento de terra & 2 \\
\hline Remessa/doações & 13 & Remessa/doações & 0 \\
\hline Outras fontes & 3 & Outras fontes & 3 \\
\hline
\end{tabular}

Fonte: Elaborada com base dos dados do SGE (2015) e nos dados calculados pela autora (2015).

Nos domicílios não familiares a aposentadoria predominou, além da renda agrícola, na maioria dos domicílios. Este cenário apontou que tais domicílios provavelmente eram compostos por pessoas mais velhas que habitavam no meio rural e obtinham os proventos advindos da previdência como um importante complemento para a sustentação de uma qualidade de vida mínima.

Os dados apontaram que outras atividades, como manufatura, turismo rural, artesanato, mostraram-se importantes na composição da renda total familiar de alguns domicílios. A presença delas por si só já 


\section{Camila Horst Toigo, Marcelo Antonio Conterato e Paulo Dabdab Waquil}

evidencia que estas não apresentam mais apenas um papel marginal na vida da população rural.

Apesar dos proventos não serem os principais fins para o alcance do bem-estar, eles são meios com importância singular para o alargamento das capacidades. Pessoas tornam-se mais vulneráveis do que as outras quando se mostram imersas na insuficiência de renda (ou pobreza monetária) (SEN, 2008, 2010). Ainda, o risco de aumentar a vulnerabilidade aumenta quando a pobreza interage com outras condições sociais que acabam reduzindo as oportunidades (UNITED NATIONS DEVELOPMENT PROGRAMME, 2014), como falta de infraestrutura, dificuldade no acesso à educação e saúde, baixa diversificação das fontes de renda, insalubridade ambiental, baixa conservação dos recursos naturais.

Tais conclusões vão ao encontro da última instância do ICV. Como exposto na Tabela 3, ao contrário das duas primeiras instâncias, nesta os domicílios de agricultura familiar apresentaram médias superiores e, portanto, percepções mais positivas em relação às suas realizações (e funcionamentos).

Embora o acesso a alguns recursos, capitais e meios terem sido percebidos com maiores dificuldades pelas famílias de agricultura familiar, como apresentado na Instância 1, supõe-se que a capacidade de agência das famílias para construir um portfólio de estratégias com a combinação dos capitais acessados e com as oportunidades surgidas a partir desses pode ter possibilitado uma realização mais positiva de alguns funcionamentos básicos, como estar nutrido, estar saudável, ter renda adequada (ver Tabela 3). Por outro lado, para os domicílios de agricultura não familiar as combinações de estratégias e capitais podem ter propiciado uma realização mais promissora, em relação aos demais domicílios, dos funcionamentos mais complexos, como ter participação na política, ter participação na própria comunidade em que vive, estar em harmonia com o meio ambiente e/ou estar preservando e conservando os recursos naturais. Porém, esta constatação não significou que os funcionamentos básicos não tenham sido alcançados pelos domicílios não familiares; apenas foram percebidos mais positivamente pelo outro grupo.

Todavia, os testes realizados de comparação de médias entre os dois grupos de domicílios resultaram na aceitação da hipótese nula. Isto é, para as três instâncias do ICV, como exposto na Tabela 5, a igualdade de médias foi constatada, afirmando a não existência de diferenças nas percepções entre os dois grupos de domicílios. 
Tabela 5 - Estatísticas do teste $\mathrm{T}$ para comparação de médias supondo variâncias diferentes - domicílios com produção familiar e não familiar

\begin{tabular}{|c|c|c|c|c|c|c|}
\hline & \multicolumn{2}{|c|}{ INSTÂNCIA 1} & \multicolumn{2}{|c|}{ INSTÂNCIA 2} & \multicolumn{2}{|c|}{ INSTÂNCIA 3} \\
\hline & $\begin{array}{l}\text { Agricultura } \\
\text { familiar }\end{array}$ & $\begin{array}{c}\text { Não } \\
\text { Familiar }\end{array}$ & $\begin{array}{l}\text { Agricultura } \\
\text { familiar }\end{array}$ & $\begin{array}{c}\text { Não } \\
\text { Familiar }\end{array}$ & $\begin{array}{l}\text { Agricultura } \\
\text { familiar }\end{array}$ & $\begin{array}{c}\text { Não } \\
\text { Familiar }\end{array}$ \\
\hline Média & 3,1590608 & 3,325255 & 3,2843915 & 3,382653 & 3,6117725 & 3,584184 \\
\hline Variância & 0,2446989 & 0,424313 & 0,2227139 & 0,260031 & 0,2285475 & 0,224211 \\
\hline Observações & 189 & 49 & 189 & 49 & 189 & 49 \\
\hline $\begin{array}{l}\text { Hipótese da } \\
\text { diferença de } \\
\text { média }\end{array}$ & 0 & & 0 & & 0 & \\
\hline gl & \multicolumn{2}{|c|}{63} & \multicolumn{2}{|c|}{71} & \multicolumn{2}{|c|}{75} \\
\hline Stat $t$ & \multicolumn{2}{|c|}{$-1,665765394$} & \multicolumn{2}{|c|}{$-1,220179556$} & \multicolumn{2}{|c|}{0,36272896} \\
\hline $\begin{array}{l}\mathrm{P}(\mathrm{T}<=\mathrm{t}) \text { uni- } \\
\text { caudal }\end{array}$ & \multicolumn{2}{|c|}{0,050362766} & \multicolumn{2}{|c|}{0,113217075} & \multicolumn{2}{|c|}{0,358913796} \\
\hline $\begin{array}{l}\text { t crítico uni- } \\
\text { caudal }\end{array}$ & \multicolumn{2}{|c|}{1,669402222} & \multicolumn{2}{|c|}{1,666599658} & \multicolumn{2}{|c|}{1,665425373} \\
\hline $\begin{array}{l}\mathrm{P}(\mathrm{T}<=\mathrm{t}) \text { bi- } \\
\text { caudal }\end{array}$ & \multicolumn{2}{|c|}{0,100725533} & \multicolumn{2}{|c|}{0,226434151} & \multicolumn{2}{|c|}{0,717827591} \\
\hline $\begin{array}{l}\text { t crítico bi- } \\
\text { caudal }\end{array}$ & \multicolumn{2}{|c|}{1,998340543} & \multicolumn{2}{|c|}{1,993943368} & \multicolumn{2}{|c|}{1,992102154} \\
\hline
\end{tabular}

Fonte: Elaborada com base nos dados do SGE (2015) e nos dados calculados pela autora.

Esses resultados trazem reflexões interessantes, visto que na literatura contemporânea sobre desenvolvimento rural e temas inerentes e, até mesmo, em muitos debates proferidos pelas elites intelectuais, a produção familiar é vista como promotora de maiores benefícios e favorecimentos à reprodução social dos indivíduos rurais. Contudo, constatou-se que para famílias produtoras no Território Rural Zonal Sul do Rio Grande do Sul, tanto famílias agricultoras com dinâmica familiar como não familiar, as percepções sobre as condições de vida não apresentavam distinções.

Todavia, é necessário destacar dois aspectos importantes. A Lei $\mathrm{n}^{\mathrm{o}}$ 11.326 de 24 de julho de 2006 estabeleceu as diretrizes, os princípios, os conceitos e os instrumentos destinados e formulados para políticas 


\section{Camila Horst Toigo, Marcelo Antonio Conterato e Paulo Dabdab Waquil}

públicas que se direcionavam aos agricultores ou empreendimentos familiares rurais (BRASIL, 2006). Para efeitos da lei, os agricultores deveriam enquadrar-se dentro de certos requisitos: não possuir área maior do que quatro módulos fiscais, utilizar preponderantemente mão de obra familiar nas atividades econômicas de seu estabelecimento, possuir um percentual mínimo de renda originada das atividades econômicas do estabelecimento e dirigir/administrar o próprio estabelecimento (BRASIL, 2005b). Deste modo, aqueles estabelecimentos e domicílios que não cumpriam alguma(s) destas condições eram considerados como de agricultura não familiar.

$\mathrm{Da}$ normatividade dos estabelecimentos rurais é que se extrai o primeiro aspecto a ser considerado: a normatividade via leis federais é importante por reconhecer a agricultura familiar como categoria social institucionalmente legitimada e fortemente representada nos sindicatos dos trabalhadores rurais (SCHNEIDER, 2007), porém, os limites da lei escondem muitas questões da vida real o que, além degerar um viés em termos analíticos, gera questionamentos sobre a sua efetiva abrangência. Aqui, fica uma reflexão importante trazida por Escher et al. (2014, p. 651): em que medida estabelecimentos que ficaram fora da normatização e foram classificados como de agricultura não familiar pode, verdadeiramente, pertencer também à agricultura familiar?

$\mathrm{O}$ segundo aspecto diz respeito à notabilidade das estratégias de reprodução social definidas pelos agricultores tornados familiares pela normatividade. Estas estratégias pautadas na diversificação dos meios de vida, como apontado por Ellis (2000), incidem não apenas no combate à pobreza, uma vez que permite a elevação da renda, mas, sobretudo, na redução das vulnerabilidades correntes e potenciais possivelmente enfrentadas pelas famílias residentes no meio rural. Por esta razão, a capacidade de acessar recursos fundamentais para propiciar autonomia, resiliência e sustentabilidade deve ser fortalecida.

Estudos como o de Escher et al. (2004), Ternoski e Perondi (2014), Vargas e Oliveira (2012) notabilizam os esforços das famílias rurais para com a sua reprodução social. Assim, estar atento aos fatores que levam as famílias a adotar estratégias diversificadas é essencial, visto que estas podem indicar falhas dos mercados, sobretudo o de crédito, tendências de choques (externos ou internos), transformação no padrão de consumo (ELLIS, 2000).

Dos resultados desta pesquisa, a reflexão primordial que se extrai é que os efeitos do desenvolvimento (percebidos através dos indicadores da Instância 3 do ICV) puderam refletir um pouco sobre a percepção em relação aos funcionamentos e realizações das famílias residentes em domicílios rurais no TZS. Embora alguns dos meios (como o acesso ao capital financeiro, por exemplo) tenham sido percebidos como debilitados 
e complexos e com restrições no seu alcance, como observado na Instância 1, a diversificação das estratégias exercidas pelas famílias produtoras (independentemente de praticarem agricultura familiar ou não) em buscar outras alternativas de sustentação e reprodução social pode ter sido o que tornou-as mais aptas para realizar e perceber melhor os funcionamentos básicos em relação às famílias não produtoras.

Todavia, deve-se estar ciente que apesar desses resultados terem sido mais positivos (em termos de percepções), estes domicílios não podem ser considerados totalmente livres de situações adversas e geradoras de vulnerabilidade. As privações percebidas podem indicar que embora a capacidade de agência possa ter sido um fator determinante para a realização de tais funcionamentos, muitas liberdades, como disponibilidade/facilidade econômica e oportunidades sociais (SEN, 2010), podem ter sido deixadas de ser alargadas em função dos obstáculos ao acesso às oportunidades.

Em suma, com vistas a responder o problema de pesquisa aqui proposto e com base nas análises e observações desenvolvidas nesta seção, infere-se que houve distinção nas percepções das condições de vida entre os domicílios com produção agropecuária e os domicílios sem produção. Alguns capitais podem ter sido acessados com maiores ou menores facilidades para o primeiro tipo de domicílio e, consequentemente, isto influenciou na realização de alguns funcionamentos específicos, na composição diferenciada dos conjuntos capacitário e nas melhores percepções.

Porém, o mesmo não se observou para os domicílios com produção familiar e não familiar. Estatisticamente, constatou-se que não houve diferença nas percepções das condições de vida de ambos. As percepções mostraram em níveis semelhantes, inclusive em termos de níveis de privações e de consagração de oportunidades. Ou seja, independentemente de serem familiares ou não, as condições de vida para ambos foram percebidas sem distinção, o que, como já tratado no decorrer do texto, traz reflexões importantes que devem ser notabilizadas.

\section{Considerações finais}

A motivação para a execução desta pesquisa se deu por diversos motivos. Primeiramente, por um aspecto metodológico, que intentou operacionalizar a Abordagem das Capacitações a partir de bases de dados primários. Ainda, há uma relevância de caráter teórico, visto que a pesquisa buscou analisar, sob um olhar multidimensional e a partir das percepções dos próprios indivíduos pesquisados, questões sociais importantes para a sociedade, como vulnerabilidade e condições de vida.

Dentre as motivações ainda se encontra o universo de análise. O ICV direciona seu estudo para unidades de investigação que pouquíssimas 


\section{Camila Horst Toigo, Marcelo Antonio Conterato e Paulo Dabdab Waquil}

ferramentas analíticas se propuseram mensurar e analisar com veemência: as regiões e populações rurais empobrecidas. O recorte geográfico do ICV não possui um caráter urbano, e é o que diferencia dos demais índices já existentes.

Portanto, em virtude do excesso de análises pautadas em indicadores estritamente econômicos e indicadores sociais limitados às dimensões que pouco avançam sobre o nível de desenvolvimento das regiões rurais, é interessante a criação de ferramentas, como o ICV, que possibilitem uma análise multifacetada do desenvolvimento. Ainda, o debate acerca da ruralidade, do desenvolvimento rural e das novas dinâmicas da agricultura, que vem ganhando força nas três últimas décadas, necessita de novos olhares na construção de políticas públicas voltadas à promoção da qualidade de vida das populações (sobretudo rurais), à valorização de novo elementos para além dos quesitos econômicos e para a eliminação de obstáculos que privam os indivíduos do acesso a recursos importantes.

Foi, então, sob esse enfoque que a análise das condições de vida dos domicílios rurais do Território Zona Sul, pautada nos conceitos senianos, levou em conta os fatores, as características e os efeitos do desenvolvimento percebidos pelas famílias rurais. Destaca-se, ainda, que foi notabilizada a liberdade e oportunidade para realizar, isto é, as facilidades de realizações, e não apenas o nível de realização em si, o que se interliga com a análise referente ao acesso aos recursos.

As diferenças nas percepções dos indivíduos residentes nos domicílios rurais produtivos e não produtivos e os diferentes resultados para os indicadores do ICV indicaram possível desigualdade de liberdades e certas privações no acesso a recursos importantes. Estes resultados direcionam-se ao questionamento sobre o quão mais resiliente uma família que, além de morar no meio rural, possui dinâmicas produtivas dentro do domicílio, é em comparação às famílias que apenas nele residem. Ainda: apesar de todo o debate não muito recente sobre as novas ruralidades e papéis do rural - que trouxeram uma revalorização de elementos antes esquecidos -, o que se tem em termos de políticas e ações das esferas públicas para promoção e aumento da qualidade de vida da população rural não está mais voltado com a questão agrária/produtiva do que com as questões humanas? E, ainda assim, não são percebidas graves limitações normativas (como no caso da lei referente ao enquadramento dos domicílios como de agricultura familiar) e de execução que, em certo grau, acabam excluindo milhares de famílias ao acesso a recursos importantes para o alargamento das suas liberdades?

Embora as percepções das famílias pesquisadas não tenham indicado condições de vida críticas, não se pode ignorar alguns resultados gerados que levam à certa preocupação (como as más condições de acesso aos mercados, políticas e programas do governo). As diferenças nas 
percepções dos indivíduos residentes nos domicílios rurais do TZS e os diferentes resultados para os indicadores do ICV indicaram possível desigualdade de liberdades e privação no acesso a recursos importantes.

Uma realidade social imersa em um cenário como este, de privações, dificuldades e obstáculos, é propícia a gerar exclusão social, baixos níveis de desenvolvimento humano e níveis significativos de pobreza e desigualdade, além de reduzir, por conseguinte, a habilidade e resiliência da população, comunidade ou indivíduo, para lidar com choques, riscos e eventos adversos. Por esta razão é de suma importância a notabilidade de trabalhos como este, que debatem sobre as dinâmicas recentes envolvendo o rural, a agricultura e o desenvolvimento a partir de uma visão multidimensional e tendo como cerne a percepção dos agentes sobre os efeitos do desenvolvimento em sua realidade social.

\section{Referências bibliográficas}

ABRAMOVAY, Ricardo. Agricultura familiar e desenvolvimento territorial. [S.1.], 1999. Disponível em: <http://ifibe.edu.br/arq/2 01508131525281087273037.pdf>. Acesso em: 26 mar. 2016.

BRASIL. Ministério do Desenvolvimento Agrário. Elaboração da proposta do Índice de Condições de Vida para aplicação nos territórios rurais (ICVTerritórios Rurais). Relatório com a proposição do Índice de Condição de Vida. Brasília: SDT/MDA, 2007.

. Lei $N^{0} 11.326$, de 24 de julho de 2006. Estabelece as diretrizes para a

formulação da Política Nacional da Agricultura Familiar e Empreendimentos Familiares Rurais. Brasília, 2006. Disponível em: <http://www.planalto.gov.br/ccivil_03/_ato2004-2006/2006/lei /111326.htm>. Acesso em: 10 ago. 2015.

Marco referencial para apoio ao desenvolvimento de territórios rurais.

Brasília: MDA/SDT, 2005b. (Documento Institucional, 2). Disponível em: <http://sge.mda.gov.br/bibli/ documentos/tree/doc_214-28-112012-11-32-675117.pdf> . Acesso em: 6 ago. 2015.

Referências para a gestão social de territórios rurais. Brasília: MDA/SDT, 2005a. (Documento Institucional, 3).

CHAMBERS, Robert; CONWAY, Gordon.Sustainable rural livelihoods: practical concepts for the 21st century. [S.1.], 1991. (IDS Discussion Paper, 296). Disponível em: <https://www.ids.ac.uk/files/Dp296.pdf>. Acesso em: 19 nov. 2014.

ELLIS, Frank. Rural livelihoods and diversity in developing countries. [S.1.]: Oxford, 2000.

ESCHER, Fabiano. Caracterização da pluriatividade e dos plurirrendimentos da agricultura brasileira a partir do Censo Agropecuário 2006. Brasília: Rev. Econ. Sociol. Rural. v.52, n.4, 2014. Disponível em: 


\section{Camila Horst Toigo, Marcelo Antonio Conterato e Paulo Dabdab Waquil}

<http://www.scielo.br/scielo.php?script=sci_arttext\&pid=S010320032014000400002> . Acesso em: 25 ago. 2016.

FERNÁNDEZ, Victor; AMIN, Ash; VIGIL, José. Repensando el desarrollo regional: contribuciones globales para una estrategia latinoamericana. Buenos Aires: Miño y Dávila, 2008.

FAVARETO, Arilson da S. Paradigmas do desenvolvimento rural em questão do agrário ao territorial. 2006. Tese (Doutorado em Ciência Ambiental) Faculdade de Economia, Administração e Contabilidade, Universidade de São Paulo, São Paulo, 2006. Disponível em:<http://www.teses.usp.br/teses/disponiveis/90/90131/tde24042008-113514/pt-br.php>. Acesso em: 5 nov. 2014.

KAGEYAMA, A. Desenvolvimento rural: conceitos e aplicações ao caso brasileiro. Porto Alegre: Editora UFRGS, 2008.

JODELET, D. Folie et représentations sociales. Paris: PUF, 1989.

MOSCOVICI, Serge. Representações sociais: investigações em psicologia social. Rio de Janeiro: Vozes, 2003.

PERONDI, Miguel Ângelo. SCHNEIDER, Sergio. Bases teóricas da abordagem de diversificação dos meios de vida. Redes, Santa Cruz do Sul, v. 17, n. 2, 2012. Disponível em: <http://online.unisc.br/seer /index.php/redes/article/view/2032>. Acesso em: 20 mar. 2016.

$\mathrm{RAMBO}$ et al. Território e desenvolvimento na escala humana:condições de vida e gestão territorial no Sul do Rio Grande do Sul. Apresentação Oral. In: CONGRESSO SOBER, 50., 2012, Vitória. Trabalhos apresentados... [S.1.]: SOBER, 2012. Disponível em: <http://www.ufrgs.br/pgdr/ publicacoes/producaotextual/marcelo-conterato/rambo-anelisegraciele-conterato-marcelo-antonio-schneider-sergio-del-re-meguigomes-carla-aldrighi-territorio-e-desenvolvimento-na-escala-humanacondicoes-de-vida-e-gestao-territorial-no-sul-do-rio-grande-do-sul-50congresso-da-sober-vitoria-es-2012>. Acesso em: 20 mar. 2016.

et al. O Índice de Condições de Vida (ICV): construindo metodologias de análise e avaliação de dinâmicas territoriais do desenvolvimento rural. Revista em Gestão, Inovação e Sustentabilidade, Brasília, v. 1, n. 1, p. 68-94, dez. 2015. Disponível em: <http://periodicos.unb.br/index.php/regis/article/view/17174>. Acesso em: 20 mar. 2016.

ROBEYNS, Ingrid. The capability approach: an interdisciplinar indtroduction. Paper presented for the Training Course preceding the 3rd International Conference on the Capability Approach, Pavia, Itália, 2003. Disponível em: <http://commonweb.unifr.ch/artsdean/ pub/gestens/f/as/files/4760/24995_105422.pdf>. Acesso em: 20 mar. 2016.

SEN, Amartya. Commodities and capabilities. New York: Oxford University Press, 1999. 
2010.

Desenvolvimento como liberdade. São Paulo: Companhia das Letras,

Desigualdade reexaminada. 2. ed. Rio de Janeiro: Record, 2008.

SCHNEIDER, Sérgio. A abordagem territorial do desenvolvimento rural e suas articulações externas. Sociologias, Porto Alegre, ano 6, n. 11, 2004. Disponível em: <http://www.scielo.br/pdf/soc/n11/n11a06.pdf> . Acesso em: 20 mar. 2016.

Teoria social, agricultura familiar e pluriatividade. RBCS, [S.1.], v.

18, n. 51, 2003. Disponível em: <http://www.scielo.br/ pdf/rbcsoc/v18n51/15988>. Acesso em: 3 nov. 2015.

. A abordagem territorial do desenvolvimento rural e suas articulações externas. Sociologias, Porto Alegre, ano 6, n. 11, 2004. Disponível em: <http://www.scielo.br/pdf/soc/n11/n11a06.pdf> . Acesso em: 20 mar. 2016.

. Tendências e temas dos estudos sobre desenvolvimento rural no Brasil.

Trabalho apresentado no XXII Congress of the European Society for Rural Sociology,Wageningen, Holanda, ago. 2007.

A pluriatividade na agricultura familiar. Porto Alegre: Editora da Universidade/UFRGS, 2009.

; FREITAS, Tanise. Qualidade de vida, diversificação e desenvolvimento: referências práticas para análise do bem-estar no meio rural. Olhares Sociais, [S.1.], v. 2, p. 121-142, 2013. Disponível em: <http://www.ufrgs.br/pgdr/publicacoes/producaotextual/Sergio $\% 20$ Schneider/schneider-s-freitas-d-t-qualidade-de-vida-diversificacao-edesenvolvimento-referencias-praticas-para-analise-do-bemestar-nomeio-rural-olhares-sociais-v-2-p-121-2013>. Acesso em: 20 mar. 2016.

TERNOSKI, Simão. PERONDI, Miguel Ângelo. As estratégias de diversificação dos meios de vida e a formação da renda: uma análise empírica sobre os estabelecimentos agrícolas familiares cooperados da Cresol Prudentópolis. [S.1] Teoria e Evidência Econômica. Ano 20, n. 43, 2014.

UNITED NATIONS DEVELOPMENT PROGRAMME - UNDP. Human development report 2014. Sustaining human progress: reducing vulnerabilities and building resilience. New York, 2014. Disponível em: <http:// www.pnud.org.br/arquivos/rdh2014.pdf>. Acesso em: 12 nov. 2015.

VAN DER PLOEG, Jan Douwe. Camponeses e impérios alimentares: lutas por autonomia e sustentabilidade na era da globalização. Porto Alegre: Editora UFRGS, 2008.

et al. Rural development: from practices and policies towards theory. Sociologia Ruralis, Oxford, v. 40, n. 4, p. 391-408, 2000. Disponível em: <http://onlinelibrary.wiley.com/doi/10.1111/1467-9523.00156/ abstract>. Acesso em: 21 mar. 2016. 


\section{Camila Horst Toigo, Marcelo Antonio Conterato e Paulo Dabdab Waquil}

VARGAS, Marco Antonio. OLIVEIRA, Bruno Ferreira de. Estratégias de diversificação em áreas de cultivo de tabaco no Vale do Rio Pardo: uma análise comparativa. Brasília: Rev. Econ. Sociol. Rural. v.50, n.1, 2012. Disponível em: http:/ / www.scielo.br/scielo.php?script=sci_arttext\&pid=S010320032012000100010. Acesso em: 25 ago. 2016.

WANDERLEY, Maria de Nazareth B. O mundo rural como um espaço de vida. Reflexões sobre a propriedade da terra, agricultura familiar e ruralidade. Porto Alegre: UFRGS, 2009.

TOIGO, Camila Horst, Marcelo Antonio Conterato e Paulo Dabdab Waquil. Domicílios rurais do Território Zona Sul: condições de vida e percepções. Estudos Sociedade e Agricultura, fevereiro de 2017, vol. 25, n. 1, p. 33-56, ISSN 1413-0580.

Resumo: (Domicílios rurais do Território Zona Sul: condições de vida e percepções). O objetivo do artigo foi verificar, a partir da análise do Índice de Condição de Vida, se as percepções sobre as condições de vida entre os domicílios rurais com produção (familiar e não familiar) e os domicílios sem produção diferiam estatisticamente. Para tanto, foram realizados testes de comparação de médias (teste $\mathrm{T}$ ) em que a hipótese nula referia-se a igualdade de médias, ou seja, igualdade nas percepções, e a hipótese não nula, o oposto. Os resultados apontaram que houve diferença nas percepções das condições de vida entre os domicílios com produção agropecuária e sem produção, isto é, aceitou-se a hipótese não nula. Porém, entre os domicílios de agricultura familiar e não familiar, a hipótese nula foi aceita.

Palavras-chave: condições de vida, domicílios rurais, percepções.

Abstract: (Rural households of the South Zone Territory: living conditions and perceptions). The aim of this research was to verify, from analysis of the Life Conditions Index, if perceptions about life conditions between rural producers' households (family farm or non-family farm) and rural non-farmer households differed statistically. Therefore, were executed means comparison tests (test-T) whose null hypothesis referred to equivalent means, that is, equal perceptions, and the non-null hypothesis, the opposite. The results showed difference in perceptions of life conditions between rural farm households and rural non-farm households, in other words, the non-null hypothesis was accepted. 
However, between family farmers' households and non-family farmers' households the null hypothesis was accepted.

Keywords: living conditions, farm household, perceptions.

Recebido em setembro de 2016. Aceito em outubro de 2016. 